https://doi.org/ 10.15407/ufm.21.01.003

\author{
A.P. SHAPOVALOV ${ }^{1,2, *}$, P. FEBVRE ${ }^{3}$, U. YILMAZ ${ }^{3}$, \\ V.I. SHNYRKOV ${ }^{4}$, M.O. BELOGOLOVSKII,5, and O.A. KORDYUK ${ }^{1,4}$ \\ ' G.V. Kurdyumov Institute for Metal Physics of the NAS of Ukraine, \\ 36 Academician Vernadsky Blvd., UA-03142 Kyiv, Ukraine \\ 2 V.M. Bakul Institute for Superhard Materials of the NAS of Ukraine, \\ 2 Avtozavodska Str., UA-04074 Kyiv, Ukraine \\ ${ }^{3}$ Université Savoie Mont Blanc, IMEP-LAHC, Campus Scientifique, \\ F-73376 Le Bourget du Lac Cedex, France \\ ${ }^{4}$ Kyiv Academic University of the NAS and MES of Ukraine, \\ 36 Academician Vernadsky Blvd., UA-03142 Kyiv, Ukraine \\ ${ }^{5}$ Vasyl' Stus Donetsk National University, 21 600-Richchya Str., \\ UA-2 1021 Vinnytsia, Ukraine
}

\title{
LOW-CAPACITANCE JOSEPHSON JUNCTIONS
}

\begin{abstract}
The Josephson effect, as an example of a macroscopic quantum phenomenon, reveals itself in the three-layer heterostructures formed by two superconductors coupled by a weak link that usually consists of a 1-2 nm-thick insulating barrier. The traditional way of modelling such-systems' dynamics is based on an equivalent circuit that comprises three parallel elements: a pure superconducting element with a certain supercurrent-versus-Josephson phase difference dependence, a resistor $R$, and a capacitor $C$. In this short review, we analyse the practical problem of reducing the junction capacitance while maintaining or slightly impairing other characteristics. Some arguments are presented to explain why the capacitance should be suppressed and how it will affect performance of superconducting quantum interference devices (SQUIDs) and digital electronics circuits. As a solution for low-capacitance junctions, we propose a weak link made of an amorphous-silicon interlayer doped with nanoscale metallic drops between the two superconducting Mo-Re-alloy electrodes.
\end{abstract}

Keywords: Josephson junctions, RCSJ model, low capacitance, doped semiconductor barriers, Mo-Re-alloy electrodes, SQUID, SFQ logic.

* shapovalovap@gmail.com

Citation: A.P. Shapovalov, P. Febvre, U. Yilmaz, V.I. Shnyrkov, M.O. Belogolovskii, and O.A. Kordyuk, Low-Capacitance Josephson Junctions, Progress in Physics of Metals, 21, No. 1: 3-25 (2020) 


\section{Introduction}

A conventional Josephson junction is made by sandwiching an ultrathin layer of a non-superconducting material between two superconducting electrodes possessing separate macroscopic wave functions, whose phase difference is $\varphi$ (see Fig. 1, $a$ ). This elementary (from the first sight) device exhibits unique and important features. Brian Josephson predicted [1] that electron pairs can flow through the weak link without any related voltage drop. The related expression (the first Josephson equation) for this DC (direct current) supercurrent being $I(\varphi)=I_{\mathrm{c}} \sin \varphi$ where $I_{\mathrm{c}}$ is the critical current. When the critical current is exceeded, a time-dependent voltage bias develops across the device such that its time average follows the second Josephson equation $d \varphi / d t=2 e \bar{V} / \hbar$. The frequency of the AC (alternating current) voltage is about $484 \mathrm{GHz}$ at $\bar{V}=1 \mathrm{mV}$. For small-area superconductor-insulator-superconductor (SIS) junctions, these two Josephson equations describe completely the nonlinear dynamics of Josephson junctions [2].

Although the fundamental nature of superconductivity, and therefore that of the junction dynamics, is quantum, in most cases, the Josephson phase may be treated as a classical continuum variable, especially when the temperatures are not too low with respect to the critical temperature $T_{\mathrm{c}}$ of the superconducting electrodes. Even more, if a pure quantum description is invoked, it is necessary to prove that the results obtained cannot be explained in 'classical' terms [3]. The modern 'classical' way of modelling the Josephson systems dynamics is based on an equivalent electrical circuit that captures the essential ingredients of a real Josephson device. It consists of three elements placed in parallel: a resistor $R$, a capacitor $C$, and a pure superconducting element with a certain supercurrent-versus-Josephson phase difference dependence. Such approach, which proved its high efficiency, is usually called as 'resistive and capacitive shunted junction' (RCSJ) model (see Fig. 1).

In this overview, we limit ourselves to this model since the main experiments, we are referring to, were performed on traditional superconductors at $4.2 \mathrm{~K}$, when the phase $\varphi$ of a Josephson device is not expected to take the attributes of a macroscopic quantum coordinate [3]. In the next subsection, we discuss details of the RCSJ model focusing on the practical problem of reducing the junction capacitance $C$ while maintaining or slightly impairing other characteristics. We present two reasons why $C$ should be suppressed and analyse from this viewpoint conventional Josephson sandwiches with insulating $(I)$ or normal-metal $(N)$ weak links between superconducting $(S)$ electrodes: SIS or SNS trilayer structure, respectively. It is argued that the problem of low capacitances cannot be solved within this elemental base and a novel solution based on doped semiconductors as non-superconducting inter- 


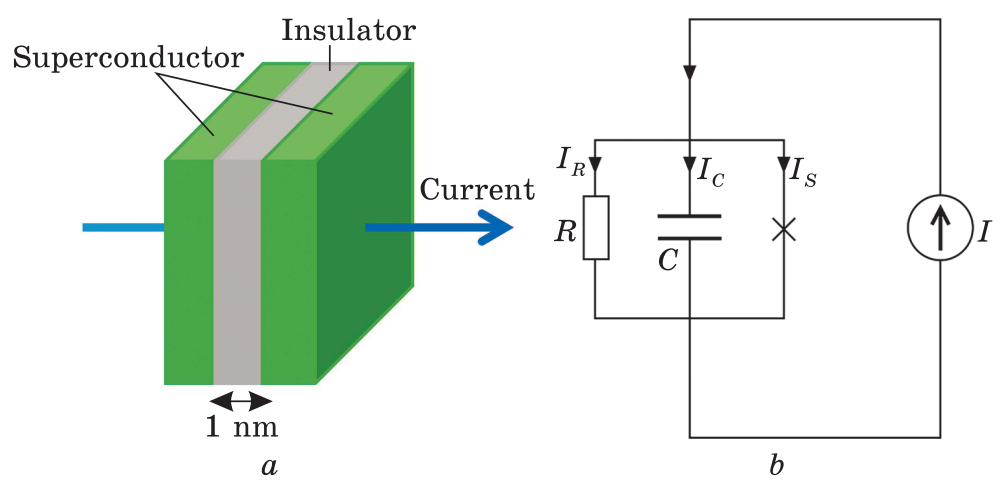

Fig. 1. Three-layer Josephson SIS junction with an insulating oxide barrier $(a)$ and its equivalent RCSJ circuit $(b)$ [2]

layers is reviewed in the third subsection. We consider a selection of essentially prototypical experiments that were carried out with such devices in different laboratories and persuade the readers to make crucial steps in this direction. In the fourth subsection, perspectives for practical applications of the semiconductor-based Josephson devices are analysed. We summarize the main messages of the overview in the conclusion.

\section{SIS and SNS Junctions}

In Figure 1, we demonstrate a conventional superconductor-insulatorsuperconductor (SIS) device proposed by Josephson [1] and an equivalent lumped-element circuit model. The junction current reads as [2]

$$
I=I_{\mathrm{c}} \sin \varphi+I_{\mathrm{qp}}(V)+C d V / d t,
$$

where $I$ and $V$ are the current and the voltage bias across the parallel combination, $C$ is the device capacitance, and $I_{\mathrm{qp}}(V)$ is the voltage-dependent quasi-particle current. The quantum-phase difference follows the second Josephson equation $d \varphi / d t=2 \pi \bar{V} / \Phi_{0}$ where $\Phi_{0}=h / 2 e$ is the magnetic flux quantum. For small junctions considered here, the dimensions are less than the Josephson penetration depth so that the phase difference $\varphi$ is uniform across the device. The junction is treated as being current-biased by the external circuitry. Let us assume that only a DC bias is present; thus, in Eq. (1), $I=I_{\mathrm{dc}}$ is a constant.

This equation is nonlinear with nonlinear coefficients. In general, the behaviour of the Josephson junction in the voltage state is governed by a complex differential equation, which has to be solved numerically in most cases. To find the dynamics of the Josephson junction we simplify the model by taking the normal resistance $R$ to be constant (RCSJ model). The Josephson junction is characterized by the Josephson coupling energy $E_{\mathrm{J}}=\hbar I_{\mathrm{c}} / 2 e$, the Josephson inductance $L_{\mathrm{J}}=\hbar /\left(2 e I_{\mathrm{c}} \cos \varphi\right)$, 
and the device resistance $R$ usually taken to be the junction resistance in the normal state. This description is indeed an approximation. Nevertheless, the RCSJ model (see Fig. 1, b) results in a still nonlinear but tractable differential equation. The equation of motion of the gaugeinvariant phase difference of a Josephson junction is equivalent to the motion of a particle, which possesses a mass proportional to the capacitance $M=C(\hbar / 2 e)^{2}$ with a damping coefficient $\eta=(\hbar / 2 e)^{2} / R$ inversely proportional to the resistance. A one-dimensional potential $U(\varphi)=$ $=E_{\mathrm{J}}\left(1-\cos \varphi-\varphi I / I_{\mathrm{c}}\right)$ is known as the tilted washboard potential.

Within the RCSJ model (Fig. 1, b), the junction operation regime is controlled by the McCumber-Stewart damping parameter $\beta_{c}$, a product of the characteristic Josephson angular frequency $\omega_{\mathrm{c}}=2 \mathrm{eV} / \hbar$, where $V_{\mathrm{c}}=I_{\mathrm{c}} R$, by the decay time $\tau=R C$ [4].

$$
\beta_{\mathrm{c}}=\frac{2 e V_{\mathrm{c}} R C}{\hbar} \text {. }
$$

From the derivation of the $\beta_{\mathrm{c}}$ parameter, it appears that non-hysteretic $I-V$ behaviour is achieved when $\beta_{c}$ is less than unity whereas for $\beta_{\mathrm{c}}>1$ the current-voltage curve will be double-valued. Without any external shunt, $R$ is the device resistance in the voltage range of operation that is usually limited by $\mathrm{eV}$ of the order of the superconducting gap. In the subgap region, the resistance of the tunnel $S I S$ junction shown in Fig. 1 is huge and, as a result, $\beta_{\mathrm{c}} \gg 1$ [4]. The most popular solution leading to single-valued characteristics is to place an external low-resistance normal-metal shunt $R_{\text {shunt }} \ll R$ in parallel with the junction that reduces the total resistance $R$ to values appropriate for $\beta_{\mathrm{c}} \approx 1$. Unfortunately, such a way results in a considerable complication of the circuitry design and introduces a parasitic inductance through the junction.

Another possibility is to diminish significantly the $S I S$ junction capacitance $C$, but this is not simple in practice since it weakly depends on the oxide-barrier modifications. For $\mathrm{Nb} / \mathrm{Al}-\mathrm{AlO}_{x} / \mathrm{Nb}$ junctions, the most popular version among the currently known SIS devices, it was shown that the specific capacitance $C_{\mathrm{s}}$ is controlled by the device normal-state resistivity $\rho_{\mathrm{N}}$ according to the empirical formula $C_{\mathrm{s}}=\mathbf{0 . 4 7 -}$ - $\left.0.047 \log \left(\rho_{\mathrm{N}}\right)\right)^{-1} \mathrm{pF} / \mathrm{cm}^{2}[6]$. As evident, the $C_{\mathrm{s}}=c_{\mathrm{s}}\left(\rho_{\mathrm{N}}\right)$ dependence is indeed very weak and, even worse, the specific capacitance increases when decreasing junction resistivity. The only possibility to suppress the total capacitance $C$ is to shrink the SIS junction size but it will result in the growth of its resistance $R$. Therefore, it is necessary to look for alternative means to diminish $C$ in order to get rid of the hysteresis in the $I-V$ curves, without reducing the product $I_{\mathrm{c}} R$ that is connected to the switching rate of the device.

Before continuing our discussion concerning possible ways to create low-capacitance Josephson junctions, let us emphasize the second reason, 
for which one needs low-capacitance Josephson devices. From Figure 1, it is evident that at very high frequencies the capacitance in the circuit with a parallel connection starts to shunt the superconducting current component due to the reduction of the corresponding reactance inversely proportional to $C$. Hence, to extend the operating frequency range of a Josephson junction, its capacitance should be as small as possible. It can be realized by replacement of the SIS device with another type of Josephson device, less resistive and at the same time with smaller capacitance.

From the first sight, the simplest way to realize it is to use a normalmetal weak link [6] instead of the insulating barrier since its resistance $R_{\mathrm{N}}$ is much lower than $R_{\mathrm{sg}}$ in the tunnel-junction realization, as well as its capacitance. In contrast to the sinusoidal dependence in SIS trilayers, the supercurrent-phase relation in $S N S$ Josephson devices is a piecewise linear function that reflects the proportionality of the superfluid velocity with the wave-function phase gradient, but with a $2 \pi$ periodicity. Due to the suppressed McCumber-Stewart damping parameter $\beta_{c}$, SNS junctions reveal inherently non-hysteretic $I-V$ curves. Moreover, in most cases, they also exhibit an extremely small capacitance and thus could be incorporated into the RCSJ-like model [7]. Unfortunately, again in contrast to SIS devices, quasi-particle excitations from a normal interlayer penetrate into the superconducting electrodes, causing suppression of superconductivity near $S N$ interfaces. In the dirty case and for conventional normal metals like $\mathrm{Au}, \mathrm{Ag}, \mathrm{Cu}$, the order-parameter suppression can exceed two orders of magnitude at $T \approx 0.5 T_{\mathrm{c}}$ [7] and it leads to a reduction of the high-frequency cut-off by orders of magnitude. This proximity effect is weakened with increasing the degree of mismatch between the electronic parameters in $S$ and $N$ metals. Hence, to use highly resistive weak-link materials is an evident way to diminish the impact of an $N$ interlayer on $S$ electrodes. According to estimations [8], the resistivity of micrometre-sized $S N S$ junctions should be not less than tens of $\mathrm{mOhm} \cdot \mathrm{cm}$ while it is $\sim 10^{-3}-10^{-2} \mathrm{mOhm} \cdot \mathrm{cm}$ in conventional $N$ metals indicated above. The capacitance of such junctions is expected to be as low as in trilayers with conventional $N$ metals.

Creating the Josephson SNS junctions with a high-resistive interlayer is possible using materials near the metal-insulator transition, with a resistivity tuned by adjusting and carefully controlling its stoichiometry. For this purpose, the authors of Ref. [9] proposed epitaxial NbN/ $\mathrm{Ta}_{x} \mathrm{~N} / \mathrm{NbN}$ trilayers deposited on the lattice-matched $\mathrm{MgO}$ substrate. Unfortunately, next investigations [8] showed large dispersions in $I_{\mathrm{c}}$ and $R_{\mathrm{N}}$ values, presumably due to the high sensitivity of the local barrier resistivity to $\mathrm{Ta}_{x} \mathrm{~N}$ stoichiometry. More prospective $\mathrm{Nb} / \mathrm{Nb}_{x} \mathrm{Si}_{1-x} / \mathrm{Nb}$ heterostructures with niobium silicide as a high-resistive material near the metal-insulator transition have been fabricated and successfully applied 
at the National Institute of Standards and Technology (U.S.A.) [10]. As found, these devices have a wide tunability range through control of the barrier composition and thickness [11, 12].

\section{Semiconductor-Based Josephson Junctions with Low Capacitance}

\subsection{Proposed Solution}

Suppressing the barrier resistance and simultaneously lower the junction capacitance is a complicated task. In order to solve it, we have to find a technologically acceptable material with a comparatively narrow gap between conduction and valence bands and a relatively low permittivity $\varepsilon$ to reduce the capacitance $C$. Unfortunately, the dielectric permittivity, and hence the capacitance, logarithmically increases with the decrease of the forbidden gap [13]. Hence, we should look for a compromise, and slightly doped silicon is, in our opinion, an optimal material in this sense.

As shown in the recent paper [14], metal nanoscale clusters with a characteristic size compared to the barrier thickness are formed in the silicon matrix of doped Si-based barrier obtained by sputtering from a composite target ( $\mathrm{Si}+$ transition metal) due to the self-organization effect. Tungsten was used as the transition metal in this case. The structural analysis showed that both silicon and tungsten are in amorphous states with this technique. Therefore, at small doping levels, the charge flow across the heterogeneous barrier is locally dependent. It rather results from transport through a large number of separate, actually one-dimensional, paths than from a uniform current across a device cross-section [15-17]. Following this hypothesis, we suppose that the main part of the eigenchannels within the hybrid barrier has a very low transmission coefficient $D \ll 1$ while a very small portion of the interface is well transparent with $D \leq 1$. The latter, most probably 'open' channels, are distributed more or less uniformly in the form of filaments or resonance-percolating trajectories [15] having a diameter much less than the superconducting coherence length $\xi_{\mathrm{s}}$ in the junction electrodes, whereas the distance between them exceeds $\xi_{\mathrm{s}}$. In this case, the proximity effect on the $S$ layers should be tiny and the superconducting order parameter, even near the $N / S$ interface, is untouched. The supercurrent that flows through the low-transparency (and thus tunnellike) part of the weak link will follow the Ambegaokar-Baratoff theory for SIS sandwiches [18] while the transport of Cooper pairs across hightransparency eigenchannels that realizes internal shunting is following the $S N S$ behaviour [7].

In our previous papers $[16,17,19]$, we argued that, in strongly disordered systems, the channel conductance $G$ depends on a single governing dimensionless parameter $Z$ in a universal way, namely, it is 
a Lorentzian $G(Z)=G_{0}\left(1+Z^{2}\right)^{-1}$ with the conductance quantum $G_{0}=$ $=2 e^{2} / h$. Let us assume next that $Z$ is a random variable uniformly distributed from zero to infinity, i.e. that its probability density follows the formula $\rho(Z)=2 \hbar \bar{G} / e^{2}=$ const [17] with the disorder-averaged macroscopic conductance $\bar{G}=\int_{0}^{\infty} \rho(Z) G(Z) d Z$. With the parametrization $D=$ $=\left(1+Z^{2}\right)^{-1}$, one can transpose $\rho(Z)$ into a distribution of local transparencies $D, \rho(D)=\rho(Z)(d Z / d D)$, and obtain at last the bimodal distribution [17]

$$
\rho(D)=\frac{\hbar \bar{G}}{e^{2}} \frac{1}{D^{3 / 2}(1-D)^{1 / 2}} .
$$

A large number of 'open' eigenchannels with the transparency $D \leq 1$ would reveal themselves, in particular, in the emergence of an excess current $I_{\text {exc }}$, a constant shift of the superconducting $I-V$ curve towards that measured in the normal state at $V$ exceeding $\Delta / e$. The ratio $I_{\mathrm{c}} / I_{\text {exc }}$ can be calculated using the universal distribution function (3) and compared with the related quantity found experimentally: it provides a second way to verify the validity of a universal distribution function. For a superconducting junction without barrier $(D=1), I_{\mathrm{c}} / I_{\mathrm{exc}} \approx 1.2$ and 1.3 at $0 \mathrm{~K}$ and $4.2 \mathrm{~K}$, respectively, whereas in the tunnelling limit $(D<1), I_{\text {exc }} \rightarrow 0$ and, hence, $I_{\mathrm{c}} / I_{\mathrm{exc}} \rightarrow \infty$. Averaging the formula for $I_{\mathrm{exc}}$ with the distribution function (3), we get $I_{\mathrm{c}} / I_{\mathrm{exc}} \approx 1.7$ and 2.4 at $0 \mathrm{~K}$ and $4.2 \mathrm{~K}$, respectively [18]. Experimental measurements on five Josephson junctions formed by superconducting Mo-Re-alloy electrodes and several-tens nm-thick Si interlayer doped by tungsten exhibited a good agreement with the theoretical prediction [17].

\subsection{Materials Deposition}

Very encouraging results on $\mathrm{Nb}$-doped $\mathrm{Si}-\mathrm{Nb}$ junctions have been also obtained in Refs. [20, 21]. In our recent papers [22-24], we have used a target consisting of a pure Si wafer and a number of tungsten wires in order to form Si tunnel barriers with nanoscale $\mathrm{W}$ dopants. The tungsten concentration $c_{\mathrm{w}}$ in the mixture was changed from 0 to 10 at.\%. Ten nanometre-thick $\mathrm{Si}(\mathrm{W})$ interlayers were deposited by DC sputtering at pressure of 0.1 $\mathrm{Pa}$ in Ar flow. Transmission electron microscopy revealed the self-organized formation of tungsten implants inside the hybrid layer [23]. Whereas, in ultra-thin $\mathrm{Si}(\mathrm{W})$ interlayers, they formed nanoclusters, their typical size for a $10 \mathrm{~nm}$-thick barrier was of the order of the barrier thickness. These results were confirmed by atomic force microscopy measurements. The dependence of the nanoclusters formation on the tungsten content was explained by substantial difference between normal gradients of Van der Waals forces for metallic tungsten and the semiconductor matrix [14]. 
Our first type of Josephson trilayers with $100 \times 100 \mu^{2}$ area was created using a traditional mask technology [22-24]. It was found that the product of the critical current and the normal-state resistance $V_{\mathrm{c}}=I_{\mathrm{c}} R_{N}$ for the $\mathrm{MoRe} / \mathrm{Si}(\mathrm{W}) / \mathrm{MoRe}$ junctions rises when the rate of simultaneous deposition of $\mathrm{Si}(\mathrm{W})$ thin films is increased. Typical $V_{\mathrm{c}}$ magnitudes as well as specific capacitance $C_{\mathrm{s}}$ and resistance $R_{N}$ values of the $\mathrm{MoRe} / \mathrm{Si}(\mathrm{W}) / \mathrm{MoRe}$ junctions agreed well with results obtained in Refs. [20, 21] for $\mathrm{Nb} / \mathrm{Si}(\mathrm{W}) / \mathrm{Nb}$ junctions. However, we believe that the replacement of niobium, an active getter, with the Mo-Re alloy leads to an increased stability of Josephson junctions.

The history of the discovery of superconductivity in the Mo-Re compound and its subsequent research during 70s and mid-80s of the last century was resumed in the introduction of the paper [25]. Superconducting properties of the Mo-Re alloy were revealed in systematic studies of the critical temperatures $T_{\mathrm{c}}$ of transition metals. As found in the 1970s, the maximum $T_{\mathrm{c}}$ in bulk and thin film Mo-Re samples is reached in the $\mathrm{A} 15$ phase and can be as high as $15 \mathrm{~K}$. It was found that in the Mo-Re system, the solubility of interstitial atoms, particularly oxygen ones, is low so that such contaminations do not depress superconductivity in the Mo-Re alloys [26]. The authors of Ref. [25] found that the native oxide of the Mo-Re alloy is grown up to a thickness not more than $0.5 \mathrm{~nm}$. The latter value is thinner that the oxides on Mo and Re surfaces. In order to form a low-leakage tunnel junction based on Mo-Re films, they had to cover it with an $\mathrm{Al}$ overlayer and to oxidize it.

Due to mechanical durability and resistance to oxygen, the Mo-Re system was proposed as a candidate for microwave cavities (see Ref. [26] and references therein). The reasons for such choice is as follows: (i) $T_{\mathrm{c}}$ of a $\mathrm{Mo}_{1-x} \mathrm{Re}_{x}$ film is usually higher than that of bulk samples, whatever technique is used for its deposition; (ii) due to the presence of the A15 metastable phase, the maximum $T_{\mathrm{c}} \cong 15 \mathrm{~K}$ is obtained for a wide range of compositions with $\mathrm{x}$ comprised between 2.5 and 6.2; (iii) high deposition temperatures are needed to achieve the maximum $T_{\mathrm{c}}$ value but critical temperatures about $11 \mathrm{~K}$ can be obtained with depositions performed at about $300^{\circ} \mathrm{C}$; (iv) Mo-Re alloys exhibit a low value of the Ginsburg-Landau parameter and consequently rather high critical field $\mathrm{H}_{\mathrm{c} 1}$ and coherence length. Due to the latter property, they are not very sensitive to small imperfections. Using the literature data for lower and upper critical magnetic fields in the Mo-Re compound, the authors of Ref. [27] estimated values of the coherence length $\xi$ to be up to $100 \mathrm{~nm}$. The energy gap $\Delta$ following from tunnelling measurements of the $\mathrm{M}_{0.6} \mathrm{Re}_{0.4}$ compound [25] is equal to $1.4 \mathrm{meV}$. Recent study [28] of full $\mathrm{Mo}_{1-x} \mathrm{Re}_{x}$ binary phase diagram showed that critical temperatures of Mo-Re alloys form three different contiguous superconducting regions. Low-temperature electronic specific heat measurements in Ref. [28] 
revealed a fully gapped superconducting state with a moderate electronphonon pairing. The unique properties of this system have attracted a renewed interest among experimentalists looking for stable and wellcontrolled superconducting heterostructures. For example, the authors of Ref. [29] studied electronic transport through single molecules with superconducting electrodes obtained by combining gold with the molybdenum-rhenium alloy.

Our new type of Mo-Re-based submicron devices with doped Si weak link were fabricated by a combination of conventional optical lithography, metal deposition and additional focused ion beam milling steps [30]. At the first stage, a three-layer MoRe-Si(W)-MoRe structure was obtained by magnetron sputtering technique. After that, pads and $5 \mu \mathrm{m}$ wide stripes were patterned with the lithography, and next, we formed submicron-size contacts by ion milling with the ion beam normal to the surface of the layered structure. At the last stage, the side cuts were made with the ion beam close to be parallel to the sample surface. Thus, the intermediate layer of doped silicon, enclosed between two side cuts, played the role of the Josephson-junction barrier through which the supercurrent $I_{\mathrm{c}}$ was flowing. Current-voltage characteristics of fabricated junctions were measured over the temperature range from 1.9 to $9.0 \mathrm{~K}$ in zero applied magnetic field and at $B=70 \mathrm{mT}$. They have exhibited a clear Fraunhofer $I_{\mathrm{c}}$-versus- $B$ pattern, where symmetry with respect to the central maximum indicates the sample homogeneity [30].

Let us now compare specific capacitances $C_{\mathrm{s}}=C / A(A$ is the device area) of Josephson junctions with a doped semiconductor barrier with those from oxide-based ones practically used in modern superconducting quantum interference devices (SQUIDs) [21, 31-35]. Low values of the specific capacitance in the case of a Josephson junction shown in the last two lines of Table $1[21,34,35]$ are due to the semiconducting barrier between superconducting electrodes that can be as thick as 20$40 \mathrm{~nm}$, while in conventional oxide-based trilayers, it is of about 1-2 nm. In the next subsection, we show that it allows increasing values $R_{\text {shunt }}$ of the shunting resistance, the transfer coefficient and the energy sensitivity of SQUIDs by 3-4 times. Even more, using doped semiconducting barriers we can create self-shunted Josephson junctions stable in time and not affected by thermal cycling.

\section{DC and RF SQUIDs with Low-Capacitance Josephson Junctions}

The superconducting quantum interference device (SQUID) [31] is a very sensitive and fast magnetometer based on superconducting loops containing Josephson junctions used to measure extremely faint magnetic fields. Some recent applications have focused on magnetic-flux measu- 
rements of superconducting quantum bits (qubits) [36] and microwave single photon counters [37,38]. The readout of macroscopic quantum states of a single superconducting qubit or that of a system of coupled qubits with the minimum back-action caused by the detector remains one of the most important engineering issues in quantum informatics. Reaching the quantum non-demolition limit is highly desirable for quantum computing [39]. It can be realized when the perturbation of the quantum state during the measurement does not go beyond that required by the measurement postulate of quantum mechanics, so that repeated measurements of the same eigenstate lead to the same outcome [40]. SQUID circuits are well suited for integration with superconducting qubits due to their low dissipation, scalability, compatibility with the qubit fabrication process and their operation in a low temperature environment.

The aim of this section is to analyse perspectives of low-capacitance Josephson junctions with a doped semiconductor barrier [14, 20, 21, 30] for improving SQUID characteristics important for a process of quantum measurements. In the following, we focus on two main types of SQUIDs: DC SQUID operating with a direct current bias and radio frequency (RF) SQUID based on the radio-frequency pumping [31].

\subsection{SQUID}

The DC SQUID consists of two Josephson junctions in parallel in a superconducting loop with the inductance [31]

$$
L \ll L_{F}=\left(\Phi_{0} / 2 \pi\right)^{2} /\left(k_{B} T\right),
$$

where $\Phi_{0}$ is the flux quantum as before and $L_{F}$ is the fluctuation inductance. The Josephson coupling energy $I_{\mathrm{c}} \Phi_{0} /(2 \pi)$ should be much larger than the thermal energy $k_{B} T$. If so, then the junction critical current $I_{\mathrm{c}}$ strongly exceeds the thermal noise current $I_{\mathrm{T}}=\left(2 \pi k_{B} T\right) / \Phi_{0}$, and it guarantees that the noise rounding of the DC SQUID currentvoltage curve will be very small. Numerical simulations show that the condition [40]

$$
I_{\mathrm{c}} \Phi_{0} / 2 \pi \approx 20 k_{B} T
$$

is sufficient for this aim. In order to eliminate hysteretic electrical characteristics and dynamical noise, the McCumber-Stewart damping parameter $\beta c$ (see Eq. (2)) should be less than unity. In SQUIDs with conventional SIS junctions, this requirement is usually achieved by using external shunt resistors $R_{\text {shunt }} \approx 2 \mathrm{Ohm}$ [39]. However, a shunt with $R_{\text {shunt }} \ll R$ reduces the voltage amplitude of the SQUID signal characteristics, and the shunting resistances can introduce intolerable back action that can cause decoherence of qubits. Therefore, the noise generated by shunting resistors should be sufficiently reduced and/or effec- 
tively decoupled from the flux qubits [36] or from the single photon counters $[14,37,38]$.

In the general case, the DC SQUID circuit is governed by a set of time-dependent nonlinear equations that should be solved numerically as a function of the McCumber-Stewart parameter $\beta_{c}$, the thermal noise parameter $\Gamma=\left(2 \pi k_{B} T\right) /\left(I_{\mathrm{c}} \Phi_{0}\right)$, and the screening parameter $\beta_{L}=2 L I_{\mathrm{c}} / \Phi_{0}$ equal to the geometrical inductance $L$ normalized by the characteristics inductance of the Josephson junction. Related numerical simulations in the classical limit $[39,40]$ show that the white noise energy of DC SQUIDs has a minimum for $\beta_{L} \cong 1, \beta_{\mathrm{c}} \cong 1$, and $\Gamma<0.05$ and that the DC SQUID maximum response occurs at the time-averaged voltage modulation $V\left(\Phi_{\mathrm{ex}}\right)$ about $I_{\mathrm{c}} R$. Then, the transfer coefficient is [31]:

$$
\eta=\partial V / \partial \Phi_{\text {ex }} \approx R / L \text {. }
$$

For small signals, the flux noise power spectral density due to thermal current fluctuations reads as [31]

$$
S_{\Phi}(f) \approx 16 k_{B} T L^{2} / R .
$$

By using $\beta_{L}=1$ and $\beta_{c}=1$, the white intrinsic energy sensitivity of the DC SQUID can be estimated as [40]

$$
\varepsilon(f)=S_{\Phi}(f) /(2 L) \approx 9 k_{B} T \Phi_{0} /\left(2 I_{\mathrm{c}} R\right)=16 k_{B} T \sqrt{L C} .
$$

Thermal noise energy (8) increases with temperature and with the $L C$ product of the DC SQUIDs. Equations (6)-(8) suggest that to enhance DC SQUID performance one should get low-capacitance Josephson junctions with the product $I_{\mathrm{c}} R$ as large as possible while keeping $\beta_{\mathrm{c}} \leq 1$ and $\beta_{L} \cong 1$. The condition $\beta_{\mathrm{c}}=1$ implies that $R \propto C^{-1 / 2}$ and, therefore, large values of $R$ require low-capacitance Josephson junctions with a doped semiconductor barrier as $\mathrm{Nb} / \mathrm{Si}(\mathrm{W}) / \mathrm{Nb}[25,26]$ and $\mathrm{MoRe} / \mathrm{Si}(\mathrm{W}) /$ MoRe [14] trilayers.

\subsection{RF SQUID}

Low-capacitance self-shunted Josephson junctions based on a doped semiconductor barrier can be used for improving RF SQUID noise performance in the ultra-high frequency regime as well. The RF SQUID consists of a superconducting loop of inductance $L$ (see Eq. (4)), interrupted by a Josephson junction, with critical current $I_{\mathrm{c}}$, capacitance $C$ and resistance $R$, coupled inductively with a matching high-quality tank circuit $L_{T} C_{T}$ excited by a current generator at the angular frequency $\omega \cong\left(L_{T} C_{T}\right)^{-1 / 2}$. When an external flux $\Phi_{\text {ex }}$ is applied, a screening current $I_{\mathrm{s}}=-I_{\mathrm{c}} \sin \varphi$ is induced in the loop, whose total flux is finally $\Phi=\Phi_{\text {ex }}-L I_{\mathrm{s}}$. The classical equation of motion for $\Phi$ is homologous to that of a particle of the mass $M=C\left(\Phi_{0} / 2 \pi\right)^{2}$ moving with damping $R^{-1}$ in a potential $U\left(\Phi, \Phi_{\text {ex }}\right)[2]$ 


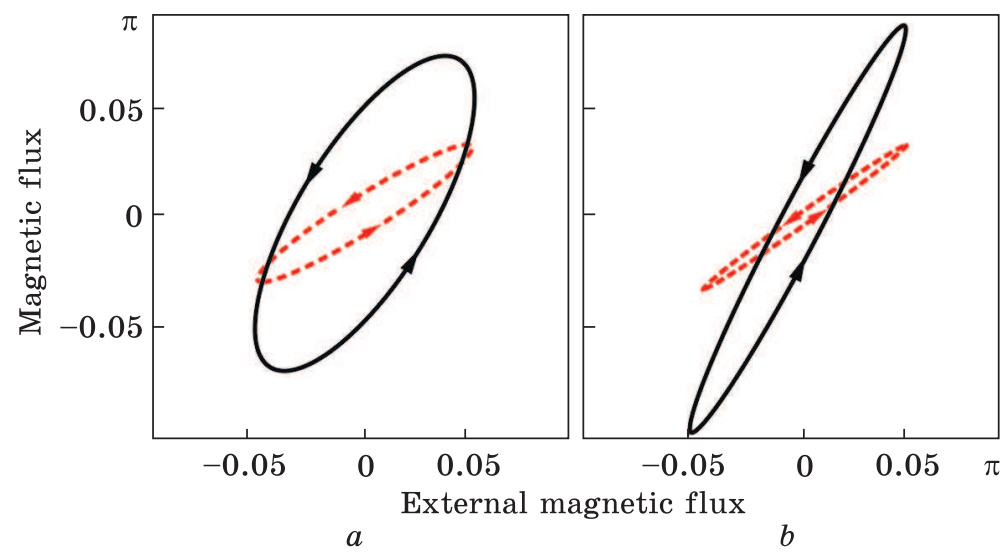

Fig. 2. Phase $\varphi\left(\varphi_{\mathrm{ex}}\right)$ trajectories for RF SQUIDs obtained as non-stationary solutions of Eq. (11) for a traditional SIS junction with a comparatively high capacitance; $l=0.5, q=0.5(a)$ and for low-capacitance doped semiconductor-based trilayer; $l=0.5, q=0.1(b)$. The amplitude of the ac contribution was fixed to $\tilde{\varphi}_{\mathrm{ex}}=0.025$, for two different values of the DC term $\varphi_{\mathrm{ex}}=0,2 \pi, 4 \pi, \ldots$ (dashed lines) and $\varphi_{\mathrm{ex}}=\pi$, $3 \pi, . .$. (solid lines). Note that the losses, proportional to the area of the $\varphi\left(\varphi_{\mathrm{ex}}\right)$ loops, are evidently smaller for a low-capacitance device [40]

$$
U\left(\Phi, \Phi_{\text {ex }}\right)=\left(\Phi-\Phi_{\text {ex }}\right)^{2} / 2 L-\left(\Phi_{0} I_{0} / 2 \pi\right) \cos \varphi .
$$

If the external flux varies slowly in time (RF SQUID with an excitation frequency much lower than $R / L$ ), then the equation describing stationary SQUID states reads

$$
\varphi+l \sin \varphi=\varphi_{\mathrm{ex}}
$$

with the dimensionless variables $\varphi=2 \pi \Phi / \Phi_{0}, \varphi_{\mathrm{ex}}=2 \pi \Phi_{\mathrm{ex}} / \Phi_{0}, l=2 \pi L I_{\mathrm{c}} / \Phi_{0}$ [2]. The quantity $l$ is a fundamental RF SQUID parameter equal to the geometrical loop inductance $L$ normalized by the characteristic inductance of the Josephson junction. SQUIDs with $l<1$ are called non-hysteretic ones. Absence of hysteresis on the magnetization curve $\varphi\left(\varphi_{\mathrm{ex}}\right)$ means that no energy is absorbed by the interferometer, i.e., it can be considered as an ideal (without losses) nonlinear reactive element of an inductive character [40]. A magnetometer based on such RF SQUID can be used to reduce the RF SQUID back action on a measured quantum system.

One can hope that the RF SQUID sensitivity and frequency band can yet be improved by increasing the excitation frequency $\omega$. Doing so, the normal current through the Josephson junction becomes of great importance. Retaining the related term, we get the following nonlinear differential equation

$$
q \dot{\varphi}+l \sin \varphi+\varphi=\varphi_{\mathrm{ex}}
$$

with $q=\omega L / R$ [2]. It has to be analysed to find the phase trajectory within the $\varphi\left(\varphi_{\mathrm{ex}}\right)$ plane. As follows from the latter equation, for a small 
ultra-high frequency excitation $\tilde{\varphi}_{\mathrm{ex}}(t)=\tilde{\varphi}_{\mathrm{ex}} \sin \omega t$, where $\tilde{\varphi}_{\mathrm{ex}}=2 \pi \tilde{\Phi}_{\mathrm{ex}} / \Phi_{0}$ is the amplitude of the AC contribution to the external flux, the $\varphi\left(\varphi_{\mathrm{ex}}\right)$ curve approaches an elliptical shape. At $l<1$ and arbitrary values of $q=\omega L / R$ numerical calculations should be performed. Our results for SQUIDs based on SIS and MoRe-Si(W)-MoRe junctions demonstrate that the presence of a characteristic time of the interferometer flux variations $\tau=L / R$ (see Fig. 2) at high $\omega$ delays a change in $\varphi$ causing thereby the deviation from the stationary solutions (10). As follows from Eq. (11), a small periodical excitation $\widetilde{\varphi}_{\mathrm{ex}}(t)=\tilde{\varphi}_{\mathrm{ex}} \sin \omega t$ added to $\varphi_{\mathrm{ex}}=$ $=$ const results in the elliptical shape of the $\varphi\left(\varphi_{\mathrm{ex}}\right)$ dependence (see Fig. 2).

Therefore, even in the non-hysteretic mode, a fraction of the external field energy has to be dissipated by the resistance $R$. It is quite natural for such shunting of the normal current to increase the ultra-high frequency SQUID nonlinearity and to reduce its response to an external magnetic flux and sensitivity. MoRe-Si(W)-MoRe junctions allow to raise values $R_{\text {shunt }}$ of the shunting resistance and characteristic frequencies by 4-5 times and respected SQUIDs with low specific capacitance and high characteristic frequencies could be applied for improving measurements of magnetic flux variations for flux qubits and single microwave photon counters.

\section{Superconducting Digital Electronics with Low-Capacitance Josephson Junctions}

Another domain that requires ideally low-capacitance Josephson devices is superconducting digital electronics based on the generation, transfer and storing of magnetic flux quanta, known as single-flux-quantum (SFQ) logic, proposed in 1991 by Likharev and Semenov [41]. In this technology, the magnetic flux quantum $\Phi_{0}$ is the physical quantity used as a vector for bits. It can take the form of quantized picosecond pulses propagating at the speed of light within the solid-state superconductor digital circuit, or of a permanent current circulating in a superconductor loop, depending if it is moving or being stored, respectively. When it is moving, the presence of a picosecond pulse passing between two given instants, usually fixed by a clock, is defined as a digital ' 1 ', while the absence of pulse corresponds to a digital ' 0 '.

\subsection{On the Maximum Speed and Thermal Noise}

SFQ logic requires Josephson junctions with non-hysteretic current-voltage characteristics to maximize the speed of circuits and to avoid slow relaxation processes. To do so, the Josephson junction should be shunted usually by adding externally in parallel a shunt resistor [42]. On the other hand, if the shunt resistor value is too low the recombination time 
of quasi-particles into Cooper pairs is slower and the circuit becomes slow again. The best trade-off is obtained for a McCumber-Stewart damping parameter $\beta_{\mathrm{c}}$ close to 1 . In this case, the optimum shunt resistance is given by [43]

$$
R_{\text {shunt }}=\frac{1}{A} \sqrt{\frac{\Phi_{0}}{2 \pi J_{\mathrm{c}} C_{\mathrm{s}}}}=\sqrt{\frac{\Phi_{0}}{2 \pi I_{\mathrm{c}} C}},
$$

where $A$ is the junction area, $J_{\mathrm{c}}$ and $C_{\mathrm{s}}$ are the critical current density of the junction and its specific capacitance, respectively. Both parameters depend on the junction barrier in an intimate way: $J_{c}$ is tightly connected to the barrier thickness while $C_{\mathrm{s}}$ depends on its physical properties. The corresponding ultimate frequency of switching is [43]

$$
f_{\max }=\sqrt{\frac{J_{\mathrm{c}}}{2 \pi \Phi_{0} C_{\mathrm{s}}}}=\sqrt{\frac{I_{\mathrm{c}}}{2 \pi \Phi_{0} C}}=\frac{R_{\text {shunt }} I_{\mathrm{c}}}{\Phi_{0}},
$$

where $C$ is the total junction capacitance. It is well known in digital electronics that a high $R_{\text {shunt }} I_{\text {c }}$ product is needed to obtain ultrafast circuits. In practice, it means (see the left term of Eq. (13)) that the current density should be very high while the specific capacitance should be low. The best case is realized when both conditions are met simultaneously.

The McCumber-Stewart parameter given by Eq. (2) can also be written under the following form [43]

$$
\beta_{\mathrm{c}}=\frac{R C}{L_{\mathrm{J} 0} / R},
$$

where $L_{\mathrm{J} 0}$ is the Josephson inductance for small currents, corresponding to a Josephson junction difference of phase close to 0 . It is the ratio of two time constants of a parallel $R L C$ circuit. From an electrical point of view, there are several ways to obtain the best performance corresponding to $\beta_{\mathrm{c}} \approx 1$ in digital mode since there are three parameters in the problem: $R, C$, and $L_{\mathrm{J} 0}$. The Josephson inductance is proportional to the inverse of the critical current of the junction; it is fixed by noise considerations. For reasons close to ones mentioned for SQUIDs in subsection 4.1, the ratio of the critical current $I_{c}$ to the thermal noise current $I_{T}$ should be large enough, typically of the order of 500 at $4.2 \mathrm{~K}$ in digital electronics [41], to avoid unwanted switching of Josephson junctions by thermal noise. This condition allows keeping an acceptable bit error rate (BER). At $4.2 \mathrm{~K}, I_{T} \approx 180$ that corresponds roughly to a minimal critical current of $I_{\mathrm{c}}=90 \mu \mathrm{A}$ and a maximum Josephson inductance $L_{\mathrm{J} 0}=3.7 \mathrm{pH}$. Increasing the area of junctions will make them more immune to noise, but at the price of a lower integration. This limits in fact the range of values accessible to $L_{\mathrm{J} 0}$. As a result, the minimum critical current is 


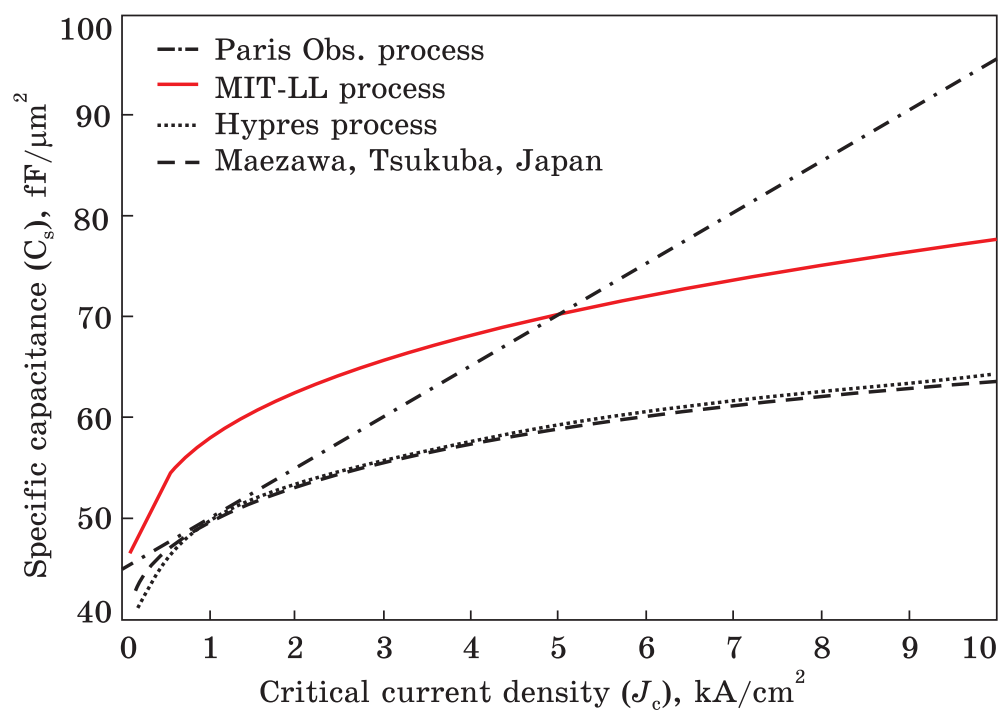

Fig. 3. Empirical laws giving specific capacitance for different $\mathrm{Nb} /$ $\mathrm{Al}-\mathrm{AlO}_{x} / \mathrm{Nb}$ processes: Paris Obs. process [53], MIT-LL process [48], Hypres process [42], and Tsukuba process [54]

fixed, as well as the maximum Josephson junction inductance. Then, there are only the capacitance $C$ and the resistance $R$ as free parameters. To obtain the maximum speed, both time constants of Eq. (14) should be about equal, leading to the determination of the resistance $R$, whose expression is given by Eq. (12). Then, the only remaining free parameter is the junction capacitance $C$. The optimum resistance value is a function of this capacitance, as can be seen in Eq. (12). Noticeably, the capacitance is in fact the only free parameter since noise considerations must be taken into account and they constraint the value of the critical current largely. That can also be seen with the maximum frequency of Eq. (13).

The current state of the art for robust fabrication processes used in digital electronics is based quasi-exclusively on $\mathrm{Nb} / \mathrm{Al}-\mathrm{AlO}_{x} / \mathrm{Nb}$ trilayers $[42,44-52]$. They exhibit specific capacitance typically in the $50-90 \mathrm{fF} / \mathrm{um}^{2}$ range, depending on the current density $J_{c}$ of the Josephson junctions, with an empirical non-physical law given by Eq. (15) for $\mathrm{THz}$ receiver technology [53], and more recent physical laws based on more measurements with Eq. (16) for Hypres Digital Foundry Technology [42], Eq. (17) for MIT-Lincoln Laboratory Foundry [48], and Eq. (18) for Electrotechnical Laboratory in Tsukuba (Japan) [54], where $J_{c}$ is in $\mathrm{kA} / \mathrm{cm}^{2}$ and $C_{\mathrm{s}}$ is in $\mathrm{fF} / \mu \mathrm{m}^{2}$. They are shown in Fig. 3,

$$
\begin{gathered}
C_{\mathrm{s}}=50+5\left(J_{\mathrm{c}}-1\right), \\
C_{\mathrm{s}}=1000 /\left(24.7-2 \ln \left(10 J_{\mathrm{c}}\right)\right),
\end{gathered}
$$




$$
\begin{gathered}
C_{\mathrm{s}}=1000 /\left(17.2-4.3 \log _{10} J_{\mathrm{c}}\right), \\
C_{\mathrm{s}}=1000 /\left(20-4.3 \log _{10} J_{\mathrm{c}}\right) .
\end{gathered}
$$

Other barriers have been proposed for digital technology. For instance, $\mathrm{NbN} / \mathrm{MgO} / \mathrm{NbN}$ junctions have been developed but they exhibit a higher specific capacitance of the order of $130 \mathrm{fF} / \mu \mathrm{m}^{2}$ [55], which ultimately limits the speed of circuits (see Eq. (13)). Consequently, most of the work to upgrade fabrication processes has focused on the increase of the critical current density with the known robust barriers based on $\mathrm{Al}$ and $\mathrm{Nb}$ oxides. By doing so, the thickness becomes so low that some pinholes can be present. Generally, the conduction mechanisms are different from those of a pure insulating thicker barrier (see the discussion in Sec. 2). The barrier becomes naturally resistive [46] and the junction starts to be self-shunted. This can be of great help to increase the integration density by removing the external shunt. In this case, the pertinent parameter is $R_{N} I_{\mathrm{c}}$ instead of $R_{\text {shunt }} I_{\mathrm{c}}$. Unfortunately, it is not easy to control independently the current density and the specific capacitance. The very thin barrier for high current densities leads also to dispersion of parameters incompatible with the requirements for large digital circuits. On the other hand, other self-shunted barriers can be engineered, as those based on silicon, which are discussed in Sec. 3. They are consequently of particular interest for digital electronics. As stated above, an ideal barrier should simultaneously exhibit a high critical current density and a low capacitance. So far, barriers based for instance on $\mathrm{Si}_{1-x} \mathrm{Nb}_{x}$ did not achieve yet this objective since their $R_{N} I_{\mathrm{c}}$ stayed at modest values below $0.36 \mathrm{mV}$ [46], while high current density $\mathrm{Al}-\mathrm{AlO}_{x}$ barriers which can achieve $R_{N} I_{\mathrm{c}}$ in the 1 to $2 \mathrm{mV}$ range do not exhibit low capacitance. Hence, the main task is now to engineer new barriers that can simultaneously meet both requirements. Figure 4 shows the maximum frequency for digital operation based on Eq. (13) calculated for different current densities and specific capacitances, considered as two independent parameters.

The prospects to obtain very low junction specific capacitances of the order of $6 \mathrm{fF} / \mu^{2}{ }^{2}$ (see Table) is appealing since, even with a lower

Table. Specific capacitance of Josephson junction barriers

\begin{tabular}{|c|c|c|}
\hline Tunnel junction & Barrier & Specific capacitance, $\mathrm{fF} / \mu \mathrm{m}^{2}$ \\
\hline $\mathrm{Nb} /$ oxide $/ \mathrm{Nb}$ & Nb oxide & $100[31]$ \\
$\mathrm{Nb} /$ oxide $/ \mathrm{Nb}$ & $\mathrm{Mg}$ oxide & $80[32]$ \\
$\mathrm{Nb} /$ oxide/ $\mathrm{Nb}$ & $\mathrm{Al}$ oxide & $60[33]$ \\
$\mathrm{NbN} / \mathrm{Si} / \mathrm{NbN}$ & amorphous $\mathrm{Si}$ & $40[34]$ \\
metal/doped $\mathrm{Si} /$ metal & Si doped with $\mathrm{W}$ & $6[21,35]$ \\
\hline
\end{tabular}




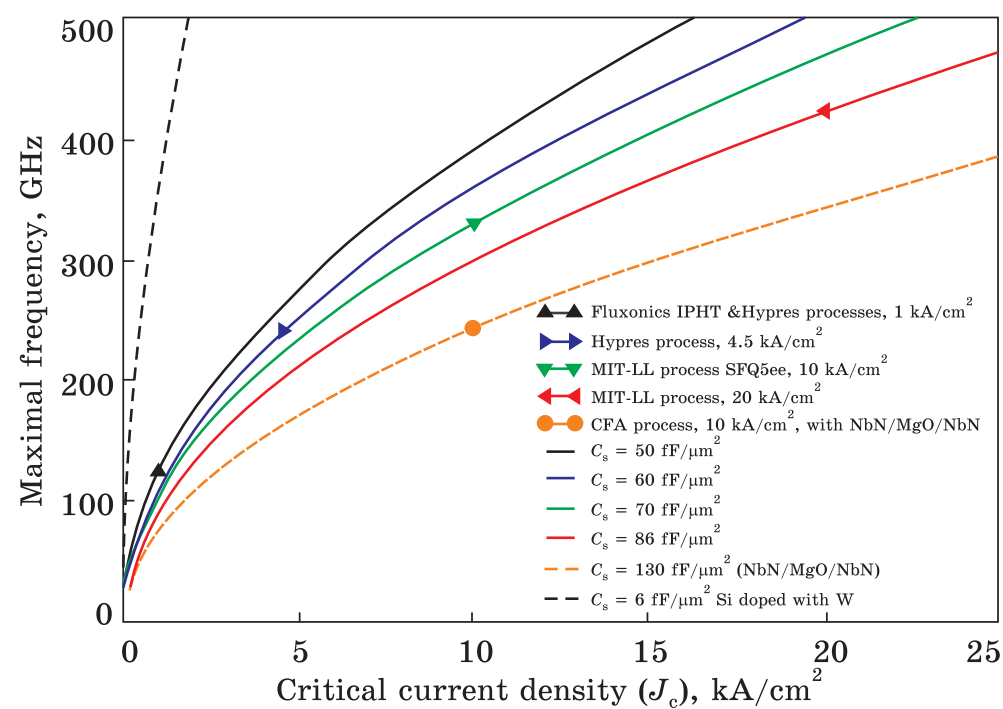

Fig. 4. Maximum expected frequency of a digital circuit as a function of the current density of a Josephson junction for different specific capacitances. $C_{\mathrm{s}}$ is considered independent on $J_{c}$. Experimental values of some of the current digital electronics fabrication processes are added as markers. Expectations with a low capacitance barrier made of silicon doped by tungsten implants are shown as well. The symbols correspond to actual fabrication processes: triangle up [42, 45], triangle right [42], triangle down [47], triangle left [48], and circles [55]

current density of the order of $1 \mathrm{kA} / \mathrm{cm}^{2}$, they could exhibit $R_{N} I_{\mathrm{c}}$ products close to $1 \mathrm{mV}$ and work at the same frequency of about $400 \mathrm{GHz}$, like the most advanced $\mathrm{Nb} / \mathrm{Al}-\mathrm{AlO}_{x} / \mathrm{Nb}$ process with a current density of $20 \mathrm{kA} / \mathrm{cm}^{2}[48]$.

\subsection{On the Engineering of Self-Shunted Barriers}

The main effect of using intrinsically self-shunted junctions is the suppression of external shunts. This allows reducing the corresponding area by one to two orders of magnitude. Doing so, the parasitic inductance associated to the external shunt resistor is also suppressed which has a positive impact of the circuit performance by reducing the junction BER due to noise [56]. Since the nature of self-shunted barriers defines simultaneously the critical current, the capacitance and the resistance, the free parameter of the external shunt adjusted to reach the maximum speed disappears. This implies that the engineering of new barriers must tackle this additional issue. In the case of a self-shunted barrier, the optimum value of the resistance of Eq. (12) becomes

$$
\rho t=\sqrt{\frac{\Phi_{0}}{2 \pi J_{\mathrm{c}} C_{\mathrm{s}}}},
$$


where $\rho$ is the barrier resistivity and $t$ is its thickness. This condition is to be taken into account to adapt the structure of the engineered barrier.

\section{Conclusions}

In this overview, we have analysed the specific capacitance of Josephson trilayers with different types of weak links. The above arguments on the example of DC SQUIDs, RF SQUIDs, and digital electronics circuits demonstrate practical relevance of reducing the junction capacitance that is often ignored in searches for optimal Josephson devices. As a solution of the problem, we have proposed a weak link made of an amorphous silicon interlayer doped by metallic nanoscale drops in-between two superconducting Mo-Re alloy electrodes. At comparatively small doping levels, the charge current across the composed barrier is locally dependent under the form of transport through a large number of separate, actually onedimensional paths rather than through a uniform current across a device cross-section. The supercurrent that flows through the low-transparency (and thus tunnel-like) part of the weak link follows the conventional theory for SIS sandwiches while the transport of Cooper pairs across hightransparency eigenchannels (in fact, internal shunts of the junction) follows the SNS behaviour. We must also point out that another practically acceptable way for controlling resistances and capacitances of trilayers with an oxide barrier could be the voltage-induced resistive switching effect in ultra-thin transition-metal oxides [57, 58]. Coexistence of memristive and meminductive memory effects is important for the development of adaptive superconducting devices and circuits [59].

Acknowledgements. The work was carried out within the framework of the joint French-Ukrainian project supported by the French-Ukrainian Partenariat Hubert Curien (Dnipro project no. 37984RL) and the Ministry of Education and Science (MES) of Ukraine (project M-62/2019).

\section{REFERENCES}

1. B.D. Josephson, Phys. Lett., 1: 251 (1962). https://doi.org/10.1016/0031-9163(62)91369-0

2. K.K. Likharev, Dynamics of Josephson Junctions and Circuits (New York: Gordon and Breach: 1986).

3. J.A. Blackburn, M. Cirillo, and N. Grønbech-Jensen, Phys. Rep., 611: 1 (2016). https://doi.org/10.1016/j.physrep.2015.10.010

4. V. Lacquaniti, D. Andreone, N. De Leo, M. Fretto, A. Sosso, and M. Belogolovskii, IEEE Trans. Appl. Supercond., 19: 234 (2009). https://doi.org/10.1109/TASC.2009.2019072

5. T. Yamamoto, S. Suzuki, K. Takahashi, Y. Yoshisato, and S. Maekawa, Appl. Phys. Lett., 66: 1000 (1995).

https://doi.org/10.1063/1.113585 
6. A.A. Golubov, M.Yu. Kupriyanov, and E. Il'ichev, Rev. Mod. Phys., 76: 411 (2004).

https://doi.org/10.1103/RevModPhys.76.411

7. L. Yu, N. Newman, J.M. Rowell, and T. Van Duzer, IEEE Trans. Appl. Supercond., 17: 3886 (2005).

https://doi.org/10.1109/TASC.2005.854302

8. L. Yu, R. Gandikota, R.K. Singh, L. Gu, D.J. Smith, X. Meng, X. Zeng, T. Van Duzer, J.M. Rowell, and N. Newman, Supercond. Sci. Technol., 19: 719 (2006). https://doi.org/10.1088/0953-2048/19/8/006

9. A.B. Kaul, S.R. Whiteley, T. Van Duzer, L. Yu, N. Newman, and J.R. Rowell, Appl. Phys. Lett., 78: 99 (2001).

https://doi.org/10.1063/1.1337630

10. D. Olaya, B. Baek, P.D. Dresselhaus, and S.P. Benz, IEEE Trans. Appl. Supercond., 18: 1797 (2008).

https://doi.org/10.1109/TASC.2008.2007652

11. D. Olaya, P.D. Dresselhaus, S.P. Benz, J. Bjarnason, and E.N. Grossman, IEEE Trans. Appl. Supercond., 19: 144 (2009). https://doi.org/10.1109/TASC.2009.2018254

12. D. Olaya, P.D. Dresselhaus, S.P. Benz, A. Herr, Q.P. Herr, A.G. Ioannidis, D.L. Miller, and A.W. Kleinsasser, Appl. Phys. Lett., 96: 213510 (2010). https://doi.org/10.1063/1.3432065

13. D.I. Sheka and A.N. Kokol, phys. stat. sol. (b), 76: 413 (1976). https://doi.org/10.1002/pssb.2220760145

14. A.P. Shapovalov, V.E. Shaternik, O.G. Turutanov, V.Yu. Lyakhno, and V.I. Shnyrkov, Low Temp. Phys., 45: 776 (2019). https://doi.org/10.1063/1.5111306

15. V. Shaternik, A. Shapovalov, M. Belogolovskii, O. Suvorov, S. Döring, S. Schmidt, and P. Seidel, Mater. Res. Exp., 1: 026001 (2014). https://doi.org/10.1088/2053-1591/1/2/026001

16. V. Lacquaniti, C. Cassiago, N. De Leo, M. Fretto, A. Sosso, P. Febvre, V. Shaternik, A. Shapovalov, O. Suvorov, M. Belogolovskii, and P. Seidel, IEEE Trans. Appl. Supercond., 26: 1100505 (2016).

https://doi.org/10.1109/TASC.2016.2535141

17. M. Belogolovskii, E. Zhitlukhina, V. Lacquaniti, N. De Leo, M. Fretto, and A. Sosso, Low Temp. Phys., 43: 756 (2017). https://doi.org/10.1063/1.4995622

18. V. Ambegaokar and A. Baratoff, Phys. Rev. Lett., 10: 486 (1963). https://doi.org/10.1103/PhysRevLett.10.486

19. V. Shaternik, M. Belogolovskii, T. Prikhna, A. Shapovalov, O. Prokopenko, D. Jabko, O. Kudrja, O. Suvorov, and V. Noskov, Phys. Procedia, 36: 94 (2012). https://doi.org/10.1016/j.phpro.2012.06.052

20. A.L. Gudkov, M.Yu. Kupriyanov, and K.K. Likharev, Sov. Phys. JETP, 67: 1478 (1988).

21. A.L. Gudkov, M.Yu. Kupriyanov, and A.N. Samus', J. Exp. Theor. Phys., 114: 818 (2012).

https://doi.org/10.1134/S1063776112030144

22. V.E. Shaternik, A.P. Shapovalov, A.V. Suvorov, N.A. Skoryk, and M.A. Belogolovskii, Low Temp. Phys., 42: 426 (2016).

https://doi.org/10.1063/1.4951668 
23. V.E. Shaternik, A.P. Shapovalov, T.A. Prikhna, O.Y. Suvorov, M.A. Skorik, V.I. Bondarchuk, and V.E. Moshchil, IEEE Trans. Appl. Supercond., 27: 1800507 (2017). https://doi.org/10.1109/TASC.2016.2636255

24. V.E. Shaternik, A.P. Shapovalov, and A.Yu. Suvorov, Low Temp. Phys., 43: 877 (2017). https://doi.org/10.1063/1.4995640

25. J. Talvacchio, M.A. Janocko, and J. Greggi, J. Low Temp. Phys., 64: 395 (1986). https://doi.org/10.1007/BF00681709

26. S.M. Deambrosis, G. Keppel, V. Ramazzo, C. Roncolato, R.G. Sharma, and V. Palmieri, Physica C, 441: 108 (2006). https://doi.org/10.1016/j.physc.2006.03.047

27. E. Rudenko, D. Solomakha, I. Korotash, P. Febvre, E. Zhitlukhina, and M. Belogolovskii, IEEE Trans. Applied Supercond., 27: 1800105 (2017). https://doi.org/10.1109/TASC.2016.2630033

28. T. Shang, D.J. Gawryluk, J.A.T. Verezhak, E. Pomjakushina, M. Shi, M. Medarde, J. Mesot, and T. Shiroka, Phys. Rev. Materials, 3: 024801 (2019). https://doi.org/10.1103/PhysRevMaterials.3.024801

29. R. Gaudenzi, O. Island, J. de Bruijckere, E. Burzur, T.M. Klapwijk, and H.S.J. van der Zant, Appl. Phys. Lett., 106: 222602 (2015). https://doi.org/10.1063/1.4922042

30. A. Kalenyuk, A. Shapovalov, V. Shnyrkov, V. Shaternik, M. Belogolovskii, P. Febvre, F. Schmidl, and P. Seidel, J. Phys. Conf. Ser. (2020) (in press).

31. R.L. Fagaly, Applied Superconductivity. Handbook on Devices and Applications (Ed. P. Seidel) (Weinheim: Wiley-VCH: 2015), p. 952.

32. A. Shoit, M. Aoyagi, S. Kosaka, F. Shinoki, and H. Hayakawa, Appl. Phys. Lett., 46: 1098 (1985). https://doi.org/10.1063/1.95774

33. M. Gurvich, M.A. Washington, and M.H. Huggins, Appl. Phys. Lett., 42: 472 (1983). https://doi.org/10.1063/1.93974

34. M. Aoyagi, A. Shoit, S. Kosaka, F. Shinoki, H. Nakagawa, S. Takada, and H. Hayakawa, Jpn. J. Appl. Phys., 23: L916 (1984). https://doi.org/10.1143/JJAP.23.L916

35. A.P. Shapovalov, V.E. Shaternik, O.G. Turutanov, O.Y. Suvorov, A.A. Kalenyuk, V.Y. Lyakhno, U. Yilmaz, P. Febvre, and V.I. Shnyrkov, Appl. Nanosci. (2020). https://doi.org/10.1007/s13204-020-01254-9

36. J. Clarke and F. K. Wilhelm, Nature, 453: 1031 (2008). https://doi.org/10.1038/nature07128

37. K. Inomata, Z. Lin, K. Koshino, W.D. Oliver, J.-S. Tsai, T. Yamamoto, and Y. Nakamura, Nat. Commun., 7: 12303 (2016). https://doi.org/10.1038/ncomms12303

38. V.I. Shnyrkov, W. Yangcao, A.A. Soroka, O.G. Turutanov, and V.Yu. Lyakhno, Low Temp. Phys., 44: 213 (2018). https://doi.org/10.1063/1.5024538

39. A. Lupaşcu, S. Saito, T. Picot, P.C. de Groot, C.J.P.M. Harmans, and J.E. Mooij, Nature Phys. 3, 119 (2007).

https://doi.org/10.1038/nphys509

40. V.I. Shnyrkov and G.M. Tsoi, Principal and Applications of Superconducting Quantum Interference Devices (Ed. A. Barone) (Singapore: World Scientific: 1992), p. 77. 
41. K.K. Likharev and V.K. Semenov, IEEE Trans. Appl. Supercond., 1: 3 (1991). https://doi.org/10.1109/TASC.2016.2630033

42. Niobium Integrated Circuit Fabrication, Process \#03-10-45, Design Rules, Revision \#25, 12/12/2012, Hypres, Inc. (2012).

43. P. Febvre, Microwave Superconducting Electronics with Josephson Devices: from Ultrasensitive Detectors for Radioastronomy to the Future Applications for the Novel Information and Communication Technologies, Habilitation Diriger des Recherches (Le Bourget du lac, France: Université Savoie Mont Blanc: 16 May 2003).

44. J. Kunert, O. Brandel, S. Linzen, O. Wetzstein, H. Toepfer, T. Ortlepp, and H.-G. Meyer, IEEE Trans. Appl. Supercond., 23: 1101707 (2013). https://doi.org/10.1109/TASC.2013.2265496

45. J. Kunert, R. Ijsselsteijn, E. Il'ichev, O. Brandel, G. Oelsner, S. Anders, V. Schultze, R. Stolz, and H.-G. Meyer, Low Temp. Phys., 43: 785 (2017). https://doi.org/10.1063/1.4995626

46. S.K. Tolpygo, V. Bolkhovsky, D.E. Oates, R. Rastogi, S. Zarr, A.L. Day, T.J. Weir, A. Wynn, and L.M. Johnston, IEEE Trans. Appl. Supercond., 28: 1100212 (2018). https://doi.org/10.1109/TASC.2018.2809442

47. S.K. Tolpygo, V. Bolkhovsky, T.J. Weir, A. Wynn, D.E. Oates, L.M. Johnson, and M.A. Gouker, IEEE Trans. Appl. Supercond., 26: 1100110 (2016). https://doi.org/10.1109/TASC.2016.2519388

48. S.K. Tolpygo, D. Yohannes, R.T. Hunt, J.A. Vivalda, D. Donnelly, D. Amparo, and A.F. Kirichenko, IEEE Trans. Appl. Supercond., 17: 946 (2007). https://doi.org/10.1109/TASC.2007.898571

49. M. Hidaka, S. Nagasawa, K. Hinode, and T. Satoh, IEICE Trans. Electronics, E91-C: 318 (2008). https://doi.org/10.1093/ietele/e91-c.3.318

50. S. Nagasawa, T. Satoh, Y. Kitagawa, M. Hidaka, H. Akaike, A. Fujimaki, K. Takagi, N. Takagi, and N. Yoshikawa, Phys. C, 469: 1578 (2009). https://doi.org/10.1016/j.physc.2009.05.219

51. S. Nagasawa and M. Hidaka, J. Phys.: Conf. Ser., 871:012065 (2017). https://doi.org/10.1088/1742-6596/871/1/012065

52. D.T. Yohannes, R.T. Hunt, J.A. Vivalda, D. Amparo, A. Cohen, I.V. Vernik, and A.F. Kirichenko, IEEE Trans. Appl. Supercond., 25: 1100405 (2015). https://doi.org/10.1109/TASC.2014.2365562

53. P. Feautrier, M. Hanus, and P. Febvre, Supercond. Sci. Technol., 5: 564 (1992) https://doi.org/10.1088/0953-2048/5/9/008

54. M. Maezawa, M. Aoyagi, H. Nakagawa, I. Kurosawa, and S. Takada, Appl. Phys. Lett., 66: 2134 (1995). https://doi.org/10.1063/1.113927

55. J.-C. Villegier, B. Delaet, V. Larrey, P. Febvre, J.W. Tao, and G. Angenieux, Phys. C, 326-327: 133 (1999). https://doi.org/10.1016/S0921-4534(99)00410-4

56. T. Ortlepp and H. F. Uhlmann, Supercond. Sci. Technol., 17: S112 (2004). https://doi.org/10.1088/0953-2048/17/5/004

57. T. Plecenik, M. Tomášek, M. Belogolovskii, M. Truchly, M. Gregor, J. Noskovič, M. Zahoran, T. Roch, I. Boylo, M. Špankova, Š. Chromik, P. Kúš, and A. Plecenik, J. Appl. Phys., 111: 056106 (2012).

https://doi.org/10.1063/1.3691598 
58. M. Truchly, T. Plecenik, E. Zhitlukhina, M. Belogolovskii, M. Dvoranova, P. Kúš, and A. Plecenik, J. Appl. Phys., 120:185302 (2016). https://doi.org/10.1063/1.4967392

59. G.U. Kamble, N.P. Shetake, S.D. Yadav, A.M. Teli, D.S. Patil, S.A. Pawar, M.M. Karanjkar, P.S. Patil, J.C. Shin, M.K. Orlowski, R.K. Kamat, and T.D. Dongale, Int. Nano Lett., 8: 263 (2018). https://doi.org/10.1007/s40089-018-0249-z

Received 02.12.2019; in final version, 13.02 .2020

А.П. Шаповалов ${ }^{1,2}$, П. Февр ${ }^{3}$, У. Їлмаз ${ }^{3}$, В.І. Шнирков ${ }^{4}$, М.О. Білоголовський ${ }^{1,5}$, О.А. Кордюк ${ }^{1,4}$

${ }^{1}$ Інститут металофізики ім. Г.В. Курдюмова НАН України, бульв. Академіка Вернадського, 36, 03142 Київ, Україна

${ }^{2}$ Інститут надтвердих матеріалів ім. В.М. Бакуля НАН України, вул. Автозаводська, 2, 04074 Київ, Україна

${ }^{3}$ Савойський університет Монблан, IMEP-LAHC, Науковий кампус, 73376 Ле Бурже-дю-Лак, Франція

${ }^{4}$ Київський академічний університет НАН України і МОН України, бульв. Академіка Вернадського, 36, 03142 Київ, Україна

5 Донецький національний університет імені Василя Стуса, вул. 600-річчя, 21, 21021 Вінниця, Україна

\section{ДЖОЗЕФСОНОВІ ПЕРЕХОДИ НИЗЬКОЇ ЄМНОСТИ}

Джозефсонів ефект, - приклад макроскопічного квантового явища, - спостерігається у тришарових гетероструктурах, утворених двома надпровідниками, сполученими слабкою ланкою, яка зазвичай складається з ізоляційного бар'єру товщиною у 1-2 нм. Традиційний спосіб моделювання динаміки таких систем базується на еквівалентній схемі, що включає три паралельних елементи: суто надпровідний елемент з певною залежністю надструму від Джозефсонової ріжниці фаз, резистор $R$ і конденсатор $C$. У цьому короткому огляді ми аналізуємо практичну проблему зменшення ємности переходу при збереженні або незначному погіршенні інших характеристик. Наведено декілька аргументів, які пояснюють, чому ємність має бути зменшеною та як вона впливатиме на параметри надпровідного квантового інтерферометра. Задля вирішення проблеми переходів низької ємности ми пропонуємо слабкі ланки, створені з аморфного кремнійового прошарку, легованого нанорозмірними металевими крапельками, між двома надпровідними електродами зі стопу Mo-Re.

Ключові слова: Джозефсонові переходи, RCSJ-модель, низька ємність, леговані напівпровідникові бар'єри, електроди зі стопу Mo-Re, HКВIД, SFQ-логіка. 
А.П. Шаповалов ${ }^{1,2}$, П. Февр ${ }^{3}$, У. Иллаз ${ }^{3}$,

В.И. Шнырков ${ }^{4}$ М.А. Белоголовский ${ }^{1,5}$, А.А. Кордюк ${ }^{1,4}$

${ }^{1}$ Институт металлофизики им. Г.В. Курдюмова НАН Украины, бульв. Академика Вернадского, 36, 03142 Киев, Украина

${ }^{2}$ Институт сверхтвёрдых материалов им. В.Н. Бакуля НАН Украины, ул. Автозаводская, 2, 04074 Киев, Украина

${ }^{3}$ Савойский университет Монблан, IMEP-LAHC, Научный кампус, 73376 Ле Бурже-дю-Лак, Франция

${ }^{4}$ Киевский академический университет НАН Украины и МОН Украины, бульв. Академика Вернадского, 36, 03142 Киев, Украина

${ }^{5}$ Донецкий национальный университет имени Василия Стуса, ул. 600-летия, 21, 21021 Винница, Украина

\section{ДЖЖОЗЕФСОНОВСКИЕ ПЕРЕХОДЫ НИЗКОЙ ЁМКОСТИ}

Эффект Джозефсона, - пример макроскопического квантового явления, - наблюдается в трёхслойных гетероструктурах, образованных двумя сверхпроводниками, соединёнными слабым связующим звеном, которое обычно состоит из диэлектрического барьера толщиной 1-2 нм. Традиционный способ моделирования динамики таких систем основан на эквивалентной схеме, которая включает в себя три параллельных элемента: сугубо сверхпроводящий элемент с определённой зависимостью сверхтока от джозефсоновской разности фаз, резистор $R$ и конденсатор $C$. В этом кратком обзоре мы анализируем практическую проблему уменьшения ёмкости перехода при сохранении или незначительном ухудшении других характеристик. Приведено несколько аргументов, поясняющих, почему ёмкость должна быть уменьшена и как она будет влиять на параметры сверхпроводящих квантовых интерференционных датчиков (СКВИДов). Для решения проблемы переходов низкой ёмкости мы предлагаем слабые связи на основе аморфного кремниевого слоя, легированного наноразмерными металлическими каплями, которые находятся между двумя сверхпроводящими электродами из сплава Mo-Re.

Ключевые слова: переходы Джозефсона, RCSJ-модель, низкая ёмкость, легированные полупроводниковые барьеры, электроды из сплава Mo-Re, CКВИД, SFQ-логика. 